\title{
BACTERIOLOGICAL PROFILE AND ANTIBIOGRAM OF UROPATHOGENS IN PEDIATRIC AGE GROUP POPULATION FROM A TERTIARY CARE HOSPITAL IN WESTERN NEPAL
}

Subhash Lal Karn, ${ }^{1}$ Ravi Kumar Kushwaha, ${ }^{2}$ Sulochana Khatiwada, ${ }^{1}$ Shristi Raut Adhikari, ${ }^{1}$ Buddhi Raj Pokhrel, ${ }^{3}$ Binaya Tamang, ${ }^{3}$ Raju Kafle ${ }^{4}$

\begin{abstract}
INTRODUCTION

Urinary tract infection (UTI) is one of the most common bacterial infections encountered in day to day pediatrics practices. It has been a significant cause of acute morbidity and is also a significant cause of hospital attendance among children. In children, despite the presence of simple and reliable methods of preliminary screening of children's urine, UTI continues to be under-diagnosed. The study aimed to know the clinical and bacteriological profile of urinary tract infection and to find out the drug resistance of bacterial isolates in pediatric age group population attending Universal College of Medical Sciences Teaching Hospital, Bhairahawa.
\end{abstract}

\section{MATERIAL AND METHODS}

Three hundred and seven non-repetitive urine samples from UTI suspected pediatric patients were included in the study and subjected for microscopic urine analysis followed by semi-quantitative culture by calibrated loop method for estimation of significant bacteriuria.

\section{RESULTS}

Present study showed that UTIs are more common in girls (54.07\%) than in boys (45.92\%). In terms of urine culture, 98 $(31.92 \%)$ subjects had positive urine culture. There was no consistent symptom common to all patients with UTI other than fever. E. coli was the commonest uropathogens isolated. E. coli was the principal isolates showing high susceptibility to Imipenem $(90.5 \%)$.

\section{CONCLUSIONS}

The result is a high percentage of resistance to commonly prescribed drugs. The urine of all suspected cases of UTI should be cultured and sensitivity pattern be determined for appropriate treatment.

KEYWORDS Bacteriological profile, Pediatric age group, Western Nepal.

1. Department of Microbiology, Universal College of Medical Sciences, Bhairahawa, Nepal.

2. B.Sc. M.L.T. student, Universal College of Medical Sciences, Bhairahawa, Nepal.

3. Department of Biochemistry, Universal College of Medical Sciences, Bhairahawa, Nepal.

4. Department of Pediatrics, Universal College of Medical Sciences, Bhairahawa, Nepal

DOI: http//doi.org/10.3126/jucms.v8i02.34287

\author{
For Correspondence \\ Subhash Lal Karn \\ Department of Microbiology \\ Universal College of Medical Sciences \\ Bhairahawa, Nepal \\ Email: subas_karna@yahoo.com
}




\section{INTRODUCTION}

Urinary tract infection (UTI) is one of the most common bacterial infections encountered in day to day pediatrics practices. Reported rates of urinary tract infection in children consulting for any acute condition vary widely from $2-20 \%$ depending on setting and inclusion criteria. ${ }^{1,2}$ It has been estimated that about 6 million patients per year are visited worldwide for UTI, out of which around 30,000 are treated in the wards. ${ }^{3}$ Urinary tract disorders in Nepal are estimated to be about $7 \%$ and urinary tract infection constitutes majorities of this disorders. ${ }^{4}$

UTI is defined as the presence of $10^{5}$ or more organisms per $\mathrm{ml}$ of urine. The incidence varies according to age, race, and sex. ${ }^{5,6}$ It is estimated that $1 \%$ of boys and $3 \%$ of girls develop UTI during the first ten years of life. ${ }^{7,8}$ It has been a significant cause of acute morbidity and is also a significant cause of hospital attendance among children. It affects male children more than females in the first year of life and female after one year of age. ${ }^{7}$ UTI is mainly due to the ascending infection from the urethra. The diagnosis of UTI in young children is important as it may be the marker of urinary tract abnormalities. Complications include renal parenchymal damage and renal scarring that can lead to hypertension and progressive renal insufficiency in later life. ${ }^{9,10}$ Diagnosis based on clinical features is difficult because of the varied nonspecific clinical features. In children, despite the presence of simple and reliable methods of preliminary screening of children's urine, urinary tract infection continues to be under diagnosed. Clinical presentation of UTI in infants and young children can be very subtle and atypical and a high index of suspension must be kept to diagnose. ${ }^{11}$ UTI in children should be suspected if there is the presence of fever, chills, and rigor, burning micturition, foul-smelling of urine, pain abdomen, vomiting, facial puffiness, loose stool, seizures, hematuria, constipation, loss of appetite, and failure to thrive.

The exact information on the etiology and resistance pattern of pediatric UTIs in a region is usually not available, and if available it is outdated as antimicrobial sensitivity patterns are bound to change over a period of time. This study was undertaken to know the clinical and bacteriological profile of urinary tract infection in children in the Universal College of Medical Sciences Teaching Hospital (UCMS-TH) which is located in the Western part of Nepal. The distribution of bacterial strains isolated from UTI and their resistance pattern against commonly used antibiotics at our setting was also studied.

\section{MATERIAL AND METHODS}

A hospital-based prospective study was conducted at UCMSTH, Bhairahawa from January 2017 to November 2017.
Ethical approval was taken from the institutional review committee (IRC) of UCMS-TH. Pediatric patients ranging from two months to 13 years of age of either sex attending pediatric outpatient department as well as in the wards with symptoms like fever, abdominal pain, dysuria, smelly urine were subjected for urine routine and microscopic examination. Sick child who were already on antibiotics were excluded from the study. Verbal consent was taken from the parents or guardians before enrolling them in the study. A detailed history of selected cases was recorded that included name, age, sex, address, duration of illness and other complaints.

Two methods were used for collecting urine for microbiological analysis: the clean-catch midstream specimen method for children who were able to control urination and the sterile plastic bags method for younger children who were not able to control urination. The choice of sampling (evacuating bladder catheter vs. spontaneous voiding) was done following accepted guidelines for each age group. ${ }^{12}$ Fifty milliliters of clean-catch midstream urine specimen was collected in a sterile universal container. The semi-quantitative technique to determine significant bacteriuria was employed by using a $0.01 \mathrm{~mL}$ calibrated wire loop to inoculate $5 \%$ blood agar and MacConkey agar with uncentrifuged urine. Culture plates were incubated at $37^{\circ} \mathrm{C}$ for 18-24 hour well-isolated bacterial colonies were processed for antibiotic sensitivity and biochemical tests. ${ }^{13}$

After the inoculation of media, the remaining sample was centrifuged at $2000 \mathrm{rpm}$ for 5 minutes and sediment was used for microscopy and Gram stain. Urine samples were examined microscopically especially for pus cells to confirm urinary tract infection via quantitative unspun wet film examination. Microscopy was done to detect pyuria ( $>1$ pus cell/ 7 high power fields), bacteriuria, hematuria of well-mixed uncentrifuged urine samples. The diagnosis of UTI was made utilizing positive urine culture for one organism with a count greater than or equal to 50,000 colony forming units (CFU) if it was collected by a urinary evacuating catheter and greater than or equal to $100,000 \mathrm{CFU} / \mathrm{ML}$, if it was collected by spontaneous voiding, according to criteria established by the American Pediatric Academy. ${ }^{14}$

The isolates were identified by standard microbiological techniques. The bacterial isolates were tested for in vitro antibiotic susceptibility by disc diffusion (Kirby-Bauer) method using Muller-Hinton agar medium as described by the National Committee for Clinical Laboratory Standards (presently called Clinical Laboratory Standard Institute). ${ }^{15}$ Antibiotics were selected according to CLSI guidelines. The antibiotic discs used for testing were selected according to CLSI (2014) schedule were amikacin $(30 \mu \mathrm{g})$, gentamicin (10 
$\mu \mathrm{g})$, cotrimoxazole $(1.25 / 23.75 \mu \mathrm{g})$, nitrofurantoin $(300 \mu \mathrm{g})$, imipenem $(10 \mu \mathrm{g})$, norfloxacin $(10 \mu \mathrm{g})$, ciprofloxacin $(5 \mu \mathrm{g})$, nalidixic acid $(30 \mu \mathrm{g})$, ceftriaxone $(30 \mu \mathrm{g})$, vancomycin $(30$ $\mu \mathrm{g})$ and clindamycin $(2 \mu \mathrm{g})$. Antibiotic discs were bought from Hi-Media diagnostic laboratory, Mumbai, India. Minimum Inhibitory Concentration (MIC) was not done.

\section{RESULTS}

Out of 307 pediatric patients suspected of UTIs enrolled in this study, the majority $183(59.60 \%)$ of cases were from the outpatient department (Figure 1).

\section{Distribution of cases}

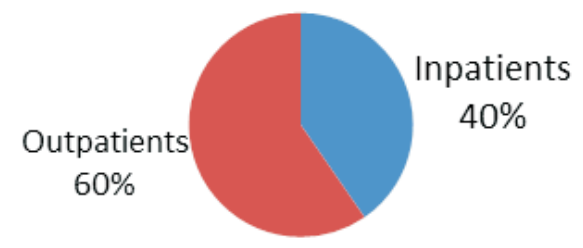

Figure 1. Total number of inpatients and outpatients taken for investigation

Of the 307 urine samples processed for routine microscopy and culture, $98(31.92 \%)$ samples showed culture positive. All suspected UITs were occurring between the ranges of 2 months to 13 years of age. The highest incidence was seen in the age group of $2-5$ years with 97 cases $(31.59 \%)$ followed by age group $0-1$ year with 80 cases $(26.05 \%)$ and $10-13$ years with 70 cases $(22.80 \%)$ which is shown in Figure 2.

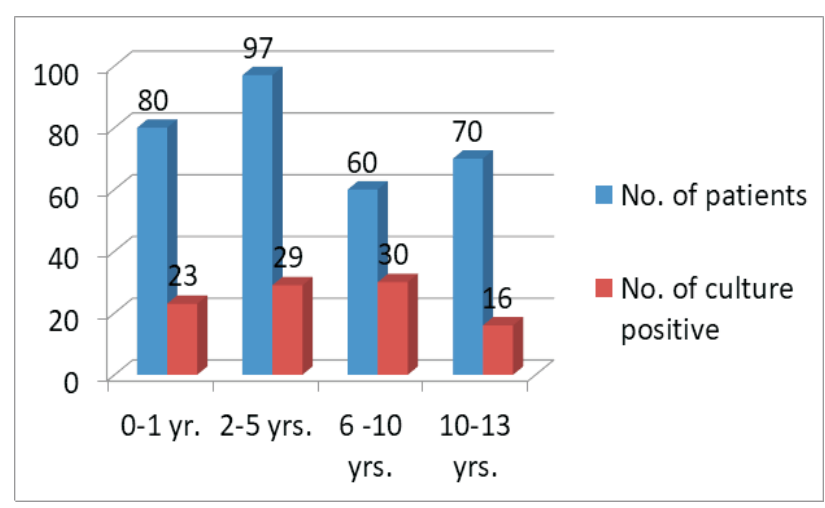

Figure 2. Total number of children (in groups) and culture positivity

Among 307 patients who had complaints related to UTI and were subjected to routine urine and culture, 166 (54.07\%) were females and $141(45.92 \%)$ were males with a male to female ratio 1:1.71 (Table1).
Table 1. Sex-wise distribution of total cases

\begin{tabular}{lcccc}
\hline & Females & Males & Total & $\begin{array}{c}\text { Male: Female } \\
\text { (Ratio) }\end{array}$ \\
\hline No. of cases & 166 & 141 & 307 & $1: 1.71$ \\
Percentage & $54.07 \%$ & $45.92 \%$ & $100 \%$ & \\
\hline
\end{tabular}

Fever was the most common presenting clinical symptom accounting for $63.51 \%$ of patients followed by nausea/vomiting $(24.42 \%)$, increased frequency of micturition (23.45\%), dysuria (22.14\%), abdominal pain (19.54\%), and headache (9.44\%) (Table 2).

\section{Table 2. Clinical manifestations of UTIs}

\begin{tabular}{lcc}
\hline Symptoms & Total & Percentage \\
\hline Fever & 195 & $63.51 \%$ \\
Headache & 29 & $9.44 \%$ \\
Nausea/ vomiting & 75 & $24.42 \%$ \\
Pain abdomen & 60 & $19.54 \%$ \\
Frequency of urine & 72 & $23.45 \%$ \\
Dysuria & 68 & $22.14 \%$ \\
Myalgia & 12 & $3.9 \%$ \\
Back pain & 15 & $4.88 \%$ \\
\hline
\end{tabular}

Urine analysis was done in all suspected cases of UTI (164; $53.42 \%$ ). Among them, 64 had $\mathrm{WBC}>10 / \mathrm{hpf}$, followed by 104 which had WBC between 6-10/hpf. Only 39 (12.70\%) had WBC 5 or less. Among all urine analyses, 162 (52.76\%) samples revealed RBCs in the urine. In terms of urine culture, $98(31.92 \%)$ subjects had positive urine culture (Table 3 ).

Table 3. Result of urine analysis and urine culture

\begin{tabular}{cc}
\hline Urine RME & Number (\%) \\
\hline Urine WBC & \\
WBC $<5 \mathrm{HPF}$ & $39(12.70 \%)$ \\
WBC 6- 10 HPF & $104(33.87 \%)$ \\
WBC $>10 \mathrm{HPF}$ & $164(53.42 \%)$ \\
Urine RBC & \\
Present & $162(52.76 \%)$ \\
Absent & $145(47.23 \%)$ \\
Urine epithelial cells & $184(59.93 \%)$ \\
Present & $123(40.06 \%)$ \\
Absent & \\
Posine cultive & $98(31.92 \%)$ \\
Negative & $209(68.07 \%)$ \\
\hline
\end{tabular}

Out of 307 cases, 98 cases showed significant bacterial growth. E. coli was the commonest uropathogens isolated in 42 pediatrics patients with a percentage of $42.85 \%$ followed by Klebsiella species 22 (22.44\%), Coagulase-negative 
staphylococci 11 (11.24\%), Staphylococcus aureus 9 (9.18\%), Non-fermenting GNB $6(6.12 \%)$, Citrobacter species 4 (4.08\%), Pseudomonas species 2 (2.045) and Enterococcus species 2 (2.04\%) as shown in Figure 3.

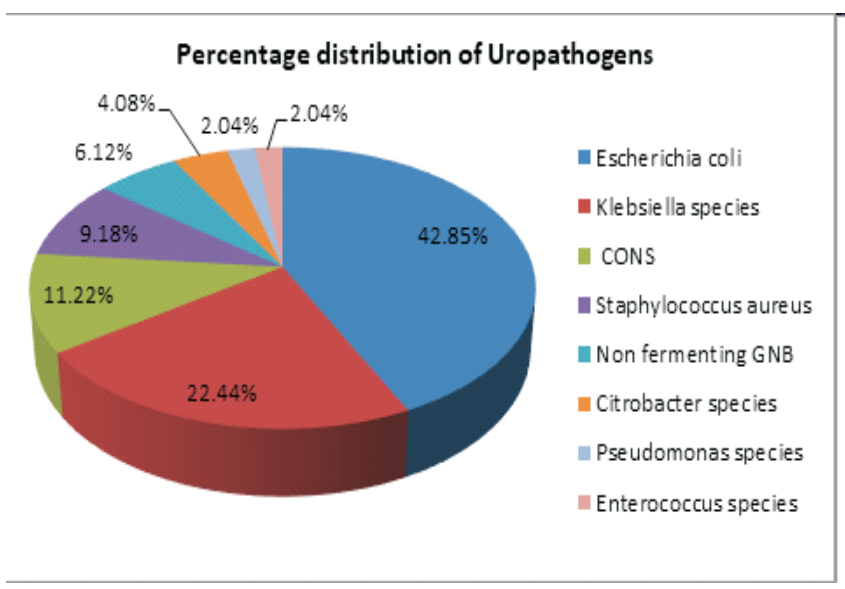

Figure 3. Different bacteria isolated from UTI cases of pediatrics patients

All the isolated Gram-negative organisms showed a high degree of sensitivity towards Imipenem. Among 76 Gram negative bacteria, E. coli showed $90.5 \%$ and $88.1 \%$ sensitivity to imipenem and amikacin respectively. While it showed less sensitivity to norfloxacin. i.e., $26.2 \%$ and least sensitive to ceftriaxone, i.e., 19.1\%. Klebsiella species have showed $81.8 \%$ sensitivity to imipenem while less sensitivity (22.7\%) to ceftriaxone (Table 4).

Table 4. Antibiotic sensitivity of common Gram-negative bacilli

\begin{tabular}{lcclll}
\hline Antibiotic & $\begin{array}{c}\text { E. coli } \\
(\mathrm{N}=42)\end{array}$ & $\begin{array}{c}\text { Klebsiella } \\
\text { species } \\
(\mathrm{N}=22)\end{array}$ & $\begin{array}{c}\text { Citrobacter } \\
\text { species } \\
(\mathrm{N}=04)\end{array}$ & $\begin{array}{c}\text { Pseudomonas } \\
\text { species } \\
(\mathrm{N}=2)\end{array}$ & $\begin{array}{c}\text { Non- } \\
\text { fermenting } \\
\text { GNB (N=06) }\end{array}$ \\
\hline Amikacin & $37(88.1 \%)$ & $18(81.8 \%)$ & $03(75 \%)$ & $01(50 \%)$ & $05(83.3 \%)$ \\
Gentamicin & $26(61.9 \%)$ & $16(72.7 \%)$ & $04(100 \%)$ & $01(50 \%)$ & $03(50 \%)$ \\
Cotrimoxazole & $19(45.2 \%)$ & $08(36.4 \%)$ & $03(75 \%)$ & $02(100 \%)$ & $03(50 \%)$ \\
Nitrofurantoin & $35(83.3 \%)$ & $14(63.6 \%)$ & $02(50 \%)$ & $01(50 \%)$ & $03(50 \%)$ \\
Imipenem & $38(90.5 \%)$ & $18(81.8 \%)$ & $04(100 \%)$ & $01(50 \%)$ & $05(83.3 \%)$ \\
Norfloxacin & $11(26.2 \%)$ & $13(59.1 \%)$ & $02(50 \%)$ & $01(50 \%)$ & $02(33.3 \%)$ \\
Nalidixic acid & $14(33.3 \%)$ & $09(40.9 \%)$ & $02(50 \%)$ & $02(100 \%)$ & $02(33.3 \%)$ \\
Ceftriaxone & $08(19.1 \%)$ & $05(22.7 \%)$ & $01(25 \%)$ & $03(100 \%)$ & $06(00 \%)$ \\
Ciprofloxacin & $32(76.2 \%)$ & $14(63.6 \%)$ & $02(50 \%)$ & $01(50 \%)$ & $03(50 \%)$ \\
\hline
\end{tabular}

The Gram-positive cocci were found to be of the sensitive variedly with high degree of sensitivity to amikacin, nitrofurantoin and followed by gentamicin and cotrimoxazole (Table 5).
Table 5. Antibiotic sensitivity patterns of Gram-positive cocci isolated

\begin{tabular}{lccc}
\hline Antibiotic & $\begin{array}{c}\text { Coagulase } \\
\text { negative } \\
\text { staphylococci } \\
\text { N=11 }\end{array}$ & $\begin{array}{c}\text { Staphylococcu } \\
\text { aureus } \\
\mathbf{N}=09\end{array}$ & $\begin{array}{c}\text { Enterococcu } \\
\text { species } \\
\mathbf{N}=02\end{array}$ \\
\hline Amikacin & $08(72.72 \%)$ & $09(100 \%)$ & $02(100 \%)$ \\
Gentamicin & $07(63.6 \%)$ & $09(100 \%)$ & $01(50 \%)$ \\
Cotrimoxazole & $08(72.7 \%)$ & $07(77.8 \%)$ & $01(50 \%)$ \\
Nitrofurantoin & $08(72.7 \%)$ & $09(100 \%)$ & $02(100 \%)$ \\
Vancomycin & $05(45.5 \%)$ & $08(88.9 \%)$ & $02(100 \%)$ \\
Clindamycin & $05(45.5 \%)$ & $09(100 \%)$ & $01(50 \%)$ \\
Ciprofloxacin & $03(27.3 \%)$ & $06(66.7 \%)$ & $02(100 \%)$ \\
Norfloxacin & $06(54.5 \%)$ & $06(66.7 \%)$ & $02(100 \%)$ \\
\hline
\end{tabular}

\section{DISCUSSION}

Urinary tract infection (UTI) is one of the commonest bacterial infections seen by Pediatricians in children. However, diagnosis remains a difficult task probably because its presentation is non-specific and similar to other common illnesses. Therefore, it is often missed in the diagnosis of children. In our study, the prevalence rate of isolation of uropathogens was $31.92 \%$ out of total of 307 urine samples from pediatrics patients. Khadka et al ${ }^{11}$ studies showed similar results with a prevalence of $28.04 \%$., whereas studies by Rai GK, et $\mathrm{al}^{12}$ and Chhetri PK, et $\mathrm{al}^{13}$ showed a slightly lower rate of isolation as $25.7 \%$ and $21.8 \%$ respectively.

Several studies in pediatrics reported female predominance, with a variable ratio. This can be easily attributed due to short urethra in females. In this study too, UTI is seen more frequently in girls $(54.07 \%)$ than in boys $(45.92 \%)$ constituting for male:female ratio as 1:1.71 which is similar to the study done by Shrestha SP, et al. ${ }^{14}$ The other probable reasons behind the low percentage of UTI among males, besides longer urethra, could be the better health care preferences to males in the Nepalese society. UTI was more common in the age group of 2-5 years with 97 cases (31.59\%) which is consistent with the findings of other studies by Singh $\mathrm{SD}$, et $\mathrm{al}^{15}$ and Jitendranath $\mathrm{A}$, et $\mathrm{al}^{16}$ also showed a common age for UTI was between two to five years. In contrast, a study by Umesh et $\mathrm{al}^{17}$ reported the majority of the patients belonged to age groups 6-10 years.

There was no consistent symptom common to all patients with UTI other than fever. In the present study, among all these children, $63.51 \%$ presented with febrile UTI. Dysuria and vomiting were the predominant symptoms. A study by Islam $\mathrm{MN}$, et $\mathrm{al}^{18}$ also indicates a high association of these symptoms and urinary tract infection. These findings indicate that clinical presentation plays a very important role in diagnosing UTI. Although clinical presentations are very strong enough, urine culture and sensitivity are essential to diagnose UTI. Among 
all urine analyses $87.3 \%$ had significant pyuria. The abovementioned result correlated with the studies done by Singh $\mathrm{SD}$, et $\mathrm{al}^{15}$ and Islam $\mathrm{MN}$, et $\mathrm{al}^{18}$ which reported the incidence of significant pyuria in $95.8 \%$ and $91 \%$ of total cases respectively.

In keeping with other studies, among those who showed positive for bacteriuria, Gram-negative organisms accounted for over $77 \%$ of the isolates with $E$. coli predominating. ${ }^{14,15} E$. coli and Klebsiella species form the bulk of organisms isolated and constitute $65.30 \%$ of all cases. This was less than that of findings reported by Rai GK, et $\mathrm{al}^{12}(93 \%)$. In this study, isolation of Gram-positive cocci was $22.44 \%$ among which CONS was the most common isolates followed by Staphylococcus aureus and Enterococcus species, which was somewhere near to that of the findings by Gupta S, et al $(21.1 \%) .^{19}$ E. coli was the principal isolates showing high susceptibility to imipenem (90.5\%), amikacin (88.1\%) followed by nitrofurantoin $(83.3 \%)$ and ciprofloxacin $(76.2 \%)$. Rodriguez Arlene ${ }^{20}$ reported imipenem as the most sensitive drug which is similar to the findings of the present study.

Similarly, in our present study, Klebsiella species were found to be sensitive to amikacin and imipenem in $(81.8 \%)$ cases whereas Citrobacter species was sensitive to gentamicin $100 \%$ and imipenem to $100 \%$. A study by Rai GK, et $\mathrm{al}^{12}$ showed that Klebsiella spp. most sensitive to ofloxacin followed by ceftriaxone and least to amikacin and nitrofurantoin. These findings are not consistent with our present study. Out of 76 Gram-negative isolates, the four highest observed resistances were for ceftriaxone $69.73 \%$, norfloxacin $61.84 \%$, nalidixic acid $61.82 \%$, and cotrimoxazole $53.94 \%$. Discussing drug sensitivity and prevalence of Gram-positive isolates will be way too early due to a smaller number of these isolates.

\section{LIMITATIONS OFTHE STUDY}

As this study is carried out among pediatric age group patients visiting our hospital, hence, this study may not reflect overall scenario of UTIs among pediatric population of this region. The study carried out among general population yields a better and reliable prevalence rate.

\section{CONCLUSION}

Culture positivity among urine specimens was found to be $31.92 \%$. UTI was commonly seen in age groups of $2-5$ years of pediatric patients. Female children are affected more than male. Escherichia coli were the most frequently isolated uropathogens followed by Klebsiella species. Among Gram positive uropathogens, CONS were most common isolates. Imipenem and amikacin were most effective drugs showing considerably highly sensitivity among Gram negative isolates, whereas amikacin, cotrimoxazole, nitrofurantoin and vancomycin showed higher sensitivity among Gram positive isolates.

\section{RECOMIMENDATION}

This type of study should be done periodically to assess the pattern of microorganisms causing UTI and their susceptibility, which will guide in the selection of antibiotics for empirical treatment. Moreover, the data would also help authorities to formulate antibiotic prescription policies, at least for a region. Present study along with previous studies indicates the need for periodic monitoring of organisms with antibiotic sensitivity of the same.

\section{ACKNOWLEDGEMENT}

We would like to acknowledge all the staffs of Department of Microbiology of UCMS-TH, Nepal.

\section{CONFLICT OF INTEREST}

The authors declare that there is no conflict of interests.

\section{REFERENCES}

1. Shaikh N, Morone NE, Bost JE, Farell MH. Prevalence of urinary tract infection in childhood: A meta-analysis. Paediatr Infec Dis J. 2008;27:302-308.

2. Hay A, Whiting P, Butler C. How best to diagnose urinary tract infection in preschool children in Primary care? British Medical Journal. 2011;343:d 6316.

3. Bano K, Khan J, Begum RH, Munir S, Akbar N, Ansari JA, Anees M. Patterns of antibiotic sensitivity of bacterial pathogens among urinary tract infections (UTI) patients in a Pakistani population. Afri. J. Microbiol. Res. 2012;6(2):41420.

4. Sharma PR. Urinary tract infection: The infection that matters. J Institute of Medicine (Nepal). 1983;5:19-22.

5. Bickertan MW, Ducket JW. Urinary tract infections in pediatric patients. American Urological Association, Houston, Texas. 1985.

6. Show KN, Gorelick M, Megowan KL and Yakscore NM. Prevalence of urinary tract infection in febrile young children in the emergency department. Pediatr. 1998;102:16-21.

7. Watson AR, Taylor CM, McGraw M, Disorder of urinary system. Forfar and Arneil's Text Book of Pediatrics, 6th edition. Neil McIntosh, Peter Helms, Rosalind Smyth. Churchill Livingstone, Spain. 2003;613-20.

8. Sharma A, Shrestha S, et al. Clinical and bacteriological profile of urinary tract infection in children; Nepal Med College Journal. 2011;13(1):24-26. 
9. Elder JS. Urinary tract infections. In: Kliegman RM, Stanton BF, St. Geme JW, Schor NF, Behrman RE, editors. Nelson Textbook of Pediatrics. $19^{\text {th }}$ ed. Philadelphia: Elsevier Saunders; 2011.pp 1829-934.

10. Srivastava RN, Bagga A, editors. Pediatric Nephrology. $5^{\text {th }}$ edition, New Delhi: Jaypee Brothers; 2011.pp 273-300.

11. Khadka Ram Bahadur, Neupane Balram, Bhandari Ravin. Bacterilogical profile of uropathogens in Pediatric patients at Crimson Hospital, Butwal, Province No. 5, Nepal. American Journal of Urology Research. SCIRES Literature. 2020;5:1.

12. Rai GK, Upreti HC, Rai SK, Shah KP, Shrestha RM. Causative agents of urinary tract infections in children and their antibiotic sensitivity pattern: A hospital-based study. Nepal Med Coll J. 2008 Jun;10(2):86-90.

13. Chhetri PK, Rai SK, Pathak UN, Thapa JB, Devkota KC, Shrestha BO, Shrestha RR. Retrospective study on urinary tract infection at Nepal Medical College Teaching Hospital, Kathmandu. Nepal Med Coll J. 2001;3:83-85.

14. Shrestha AK, Shrestha SP, Lamsal I, Joshi M. Bacteriological profile of urinary tract infection in children at GMC Teaching Hospital. Journal of Chitwan Medical College 2013;3(5)

15. Singh SD, Madhup SK, Clinical profile and antibiotic sensitivity in childhood urinary tract infection at Dhulikhel Hospital. Kathmandu University Medical Journal. 2013 OctDec;Vol.11 No.4 Issue 44.

16. Jitendranath A, Radhika R, Bhargavi L, et al. Microbiological profile of urinary tract infection in pediatric population from a tertiary care hospital in South Kerala. J Bacteriol Mycol Open Access. 2015;1(1):4-7.

17. Umesh, Padmavati Bisht and Sushma Tamta. Microbiological profile in urinary tract infections among children in a tertiary care center in Kumaun region, India, International Journal of Current Microbiology and Applied Sciences. 2016;5(4):101108.

18. Islam MN, Khaleque MA, Siddika M, Hossain MA. Urinary tract infection in children in a tertiary level hospital in Bangladesh. Mymensingh Med J. 2010 Oct;19(4):482-6.

19. Gupta S, Agarwal R, et al. Urinary tract infection in pediatric patients in North India. IOSR Journal of Dental and Medical sciences (IOSR-JDMS). Nov-Dec 2013;11(3):58-62.

20. Rodriguez Encarnacion A. Pathogens causing urinary tract infection and their resistance patterns among pediatric patients in Chong Hua Hospital. Pediatr Infect Dis Soc Philipp J. 2012;13:37-43. 